\title{
Olfaction and Aging: A Review of the Current State of Research and Future Directions
}

i-Perception 202I, Vol. 12(3), I-24

(C) The Author(s) 2021

DOI: 10.1177/204166952II02033। journals.sagepub.com/home/ipe @SAGE

\section{Jonas K. Olofsson (D)}

Gösta Ekman Laboratory, Stockholm University, Stockholm, Sweden; Department of Psychology, Stockholm University, Stockholm, Sweden

\section{Ingrid Ekström}

Aging Research Center, Karolinska Institutet and Stockholm University, Stockholm, Sweden

\section{Maria Larsson}

Gösta Ekman Laboratory, Stockholm University, Stockholm, Sweden; Department of Psychology, Stockholm University, Stockholm, Sweden

\section{Steven Nordin}

Department of Psychology, Umeå University, Umeå, Sweden

\begin{abstract}
Olfaction, the sense of smell, is characterized by a notable age-dependency such that aging individuals are more likely to have poor olfactory abilities. These impairments are considered to be mostly irreversible and as having potentially profound effects on quality of life and food behavior, as well as constituting warning signs of mortality, cognitive dysfunction, and dementia. Here, we review the current state of research on aging and olfaction, focusing on five topics which we regard to be of particular relevance for the field: nutrition and health, cognition and dementia, mortality, environment and genetics, and training-based enhancement. Under each of these headlines, we provide a state-of-the-art overview and discuss gaps in our knowledge which might be filled by further research. Understanding how olfactory abilities are diminished in aging, and how they may be alleviated or recovered, involves a set of challenging tasks for researchers in the years to come.
\end{abstract}

\section{Corresponding author:}

Jonas K. Olofsson, Department of Psychology, Stockholm University, Frescati Hagväg 9, Stockholm SE-I069I, Sweden. Email: Jonas.Olofsson@psychology.su.se 


\section{Keywords}

chemosensory, development, lifespan/aging, memory, perception

Date received: 30 October 2020; accepted: 21 April 202I

\section{Introduction}

Smell loss is an invisible impairment in many aging persons. Whereas all sensory systems undergo changes with age, the changes observed in the olfactory system have unique causes as well as unique consequences for health and well-being. There is no corrective technology for olfaction that would correspond to hearing aids or eye-glasses. However, age-related olfactory changes are neither ubiquitous, nor are they always irreversible. There is reason to discuss these age-related changes in depth. In this review, we focus on some of the major topics in research on olfactory function in aging and provide recommendations for future research. We will initially provide a state-of-the-art review of age-associated olfactory changes, to be followed by an overview of five emerging topics which are deemed to be of particular interest, and for which new developments are to be expected in the coming years. These topics are nutrition and health, cognition and dementia, mortality, environment and genetics, and training-based enhancement. As our review spans a wide range of topics, it is not exhaustive, yet it discusses many of the key concepts, references, and emerging trends in the field.

Olfaction is multifaceted, and is often assessed by sensory detection thresholds (differentiating faint odors from no-odor control stimuli), discriminating between odor qualities (detecting a deviant quality among identical control stimuli), and cued identification of everyday odors (accurately matching odors to labels in a list; Doty et al., 1984; Oleszkiewicz et al., 2019). Identification of everyday odors may also be assessed without the provision of contextual cues (i.e., free odor identification or odor naming) which is a cognitively effortful task (Larsson et al., 2016; Olofsson et al., 2013). A vast number of studies demonstrated impaired olfactory functions in aging (Choi et al., 2018; Hedner et al., 2010; Hummel et al., 1997; Kern et al., 2014; Larsson et al., 2000; Larsson, Hedner, et al., 2009; Schubert et al., 2017; Stuck et al., 2006). Age-related impairment is pronounced in odor quality discrimination (Choudhury et al., 2003; Hedner et al., 2010; Hummel et al., 1997; Kaneda et al., 2000) as well as in odor intensity ratings (S. Koskinen \& Tuorila, 2005). Diminished odor intensity perception, as well as pronounced olfactory adaptation and slower recovery from adaptation, was suggested already in early work on aging and olfaction (J. C. Stevens \& Cain, 1985, 1987; J. C. Stevens et al., 1982, 1989; Wysocki \& Gilbert, 1989). Interestingly, psychophysical studies suggest largely independent, parallel processing of odor intensity and quality discrimination, as well as of odor detection and quality discrimination (Cain et al., 2008; Rawson et al., 1998; Savic et al., 2000; de Wijk \& Cain, 1994). Hence, for example, a mild-to-moderate loss in detection sensitivity may not necessarily be accompanied by a loss in quality discrimination for suprathreshold odors.

As is true for other senses, olfactory abilities rely on both sensory and cognitive processes. Detection and quality discrimination are often referred to as tasks that mainly draw on sensory abilities, and perceived odor intensity, while driven by the magnitude of the stimulus, also provides a reflection of sensory acuity. Odor identification requires some detection sensitivity (assumed to underlie relatively strong odor sensations), quality discrimination, and cognitive or transmodal abilities such as recognition memory, odor-visual integration, 
semantic knowledge, or word retrieval (Hedner et al., 2010; Larsson et al., 2005; Olofsson \& Gottfried, 2015), which all are important for human daily routines (Croy et al., 2014). As would be expected based on their declining olfactory abilities, aging persons are often clearly impaired in odor identification tasks (Hedner et al., 2010; Hummel et al., 1997; Kern et al., 2014; Larsson et al., 2000, 2004; Makowska et al., 2011; Menon et al., 2013; Olofsson et al., 2010; Pinto et al., 2014; Schubert et al., 2011; Wehling et al., 2011; Wilson et al., 2011; Wong et al., 2010). Prevalence rates for olfactory dysfunction, based on cued odor identification, increase from $11 \%$ to $24 \%$ in middle-aged individuals to $37 \%$ to $70 \%$ at the age of 70 years (Brämerson et al., 2004; Murphy et al., 2002; see also Choi et al., 2018; Hoffman et al., 2016; Seubert et al., 2017). Results from longitudinal studies suggest that these findings cannot simply be attributed to cohort effects (Schubert et al., 2011; Wehling, Lundervold, et al., 2016). Other cognition-dependent olfactory functions impaired in aging are episodic odor recognition memory, perception of odor familiarity, and edibility judgments (Larsson \& Bäckman, 1993, 1997; Murphy et al., 1997; Wehling, Wollschlaeger, et al., 2016). Olfaction thus involves many facets, most of which are challenged by aging processes.

In accordance with results on orthonasal olfaction, aging-related impairments in retronasal olfaction are observed in detection, quality and intensity discrimination (Cain et al., 1990; Duffy et al., 1999; S. Koskinen \& Tuorila, 2005; J. C. Stevens \& Cain, 1993), perceived intensity (J. C. Stevens \& Cain, 1986), and identification (Murphy, 1985). Furthermore, de Graaf et al. (1994) reported that aging adults, on average, perceive high concentrations of food flavors to be less intense than do younger adults, and that the optimal pleasantness concentrations of the flavors are higher in old age.

Persons with declining olfactory functions often report a diminished quality of life, negative effects on interpersonal relations, worries about not perceiving toxic substances, poor control over personal hygiene, difficulties with daily routines, and depression (Boesveldt, Postma et al., 2017; Croy et al., 2014). It is unfortunately common among aging persons to be unaware of having poor olfactory abilities (Bahar-Fuchs et al., 2011; Nordin et al., 1995; Rawal et al., 2014; Seubert et al., 2017; Wehling et al., 2011, 2015; White \& Kurtz, 2003). Recent longitudinal research, however, provides a slightly more optimistic view, as selfreported olfactory decline often reflect objective olfactory decline, at least in cognitively intact aging adults (Ekström et al., 2019). Nevertheless, a rather large proportion of aging adults may constitute a risk group with respect to safety issues (e.g., detection of smoke, gas leaks, and spoiled food).

The age-related changes in olfactory function described earlier depend on anatomical and physiological changes such as a decreased number of olfactory receptor cells, reduced volume of olfactory brain regions such as the olfactory bulb, amygdala, piriform cortex, anterior olfactory nucleus, and frontal poles as well as broader electrophysiological tuning curves for receptor cells (Attems et al., 2015; Doty \& Kamath, 2014; Rawson, 2006). Aging-related olfactory loss is also associated with cortical processing changes, such as a diminished cortical processing speed (Lötsch \& Hummel, 2006; Murphy et al., 2000; Morgan \& Murphy, 2010; Stuck et al., 2006) and decreased odor-elicited activity in the enthorinal cortex, piriform cortex, amygdala and periamygloid cortex, hippocampus and parahippocampal gyrus, orbitofrontal cortex, and insula and perisylvian zones (Cerf-Ducastel \& Murphy, 2003; Suzuki et al., 2001; Yousem et al., 1998; Wang et al., 2005, 2017). Regarding age-related neurochemical changes, acetylcholine is of particular interest as it is a neurotransmitter critical for the olfactory system and has shown deficiency in the aging brain (Doty \& Kamath, 2014). Furthermore, nigrostriatal dopaminergic degeneration (Wong et al., 2010) and age-related reductions in the binding potential for the striatal dopamine transporter in putamen (Larsson, Farde, et al., 2009) may be linked to olfactory decline in aging. 
Despite the multifaceted nature of age-related olfactory loss, it may be at least partly avoidable; so-called successfully-aged persons have a reduced risk of age-related impairment in olfactory detection sensitivity (Nordin et al., 2012). In line with this finding, poorer odor sensitivity has been reported in institutionalized compared with independently living aging persons (Sulmont-Rosse et al., 2015). Based on what is known about olfaction and aging, we will review five domains where the age-associated olfactory dysfunction is of particular interest, and where more research is needed to facilitate olfactory-related health and wellbeing in the aging population.

\section{Nutrition and Health}

Malnutrition is a major concern regarding the aging population, in particular among the institutionalized aging persons. Between $3 \%$ and $10 \%$ of independently living aging adults and $25 \%$ to $60 \%$ of institutionalized aging adults suffer from malnutrition. The problem is particularly common in nursing homes, with prevalence rates of up to $85 \%$ (Saletti et al., 2000; Swedish National Food Administration, 1998; Vellas et al., 2001). Malnutrition among aging adults can largely be attributed to aging-related anorexia, which is due to various social, psychological, and biological factors that include disease (Brownie, 2006; Donini et al., 2003).

The olfactory system plays key roles in determining when we decide to start eating, how much to eat, and what to eat. The onset is partly determined by hunger and food cravings. Food odors encourage food intake, for example, by secreting insulin that lowers the bloodglucose level and generates a hunger sensation. The odors may also trigger secretion of saliva, gastric acids, and enzymes as well as cardiovascular and thermal responses to prepare for metabolization (Richardson et al., 1977). So-called learned sensory control has been associated with onset of a meal in which food cravings are evoked by classical conditioning (De Houwer et al., 2001). During a meal, some mechanisms enhance continued eating, whereas others enhance its termination (Davis \& Levine, 1977). The former group includes odor sensations that release dopamine, activating the "reward system," and serotonin, evoking well-being to encourage continued eating (E. T. Rolls, 2015). The orbitofrontal cortex, insula, and amygdala play important roles in this context. Learned sensory control can contribute to termination of the meal. For example, it was early shown that calorie content can be predicted based on the flavor, and that the meal size can be adjusted depending on the flavor (Birch \& Deysher, 1986). Finally, food preference and aversions strongly affect what we decide to eat, explained by classical and instrumental conditioning. We learn early in life, primarily based on olfactory cues, to identify an item with respect to its edibility (Schaal et al., 1998). Preferences begin to form even before birth by flavors in the amniotic fluid from the mother's food intake (Mennella \& Beauchamp, 1993; Mennella et al., 1995). Regarding food aversions, olfactory signals evoke nausea and vomiting that underlie the aversions, and odor-based associations of this kind appear to be the most common reason for a food aversion (Nordin et al., 2004).

Age-related changes in sensory perception are likely to contribute considerably to anorexia of aging (MacIntosh et al., 2000). Perception of food is multisensory, involving olfaction, gustation, chemical and nonchemical skin senses, vision, audition, and kinesthesis; these senses provide information about the food's flavor, temperature, color, appearance, and texture. Olfaction appears to shape food choice and intake, whereas taste has an important role as a macro-nutrient sensing system (Boesveldt \& de Graaf, 2017).

Given the importance of olfaction for eating behavior, its impairment may be accompanied by impact on food intake and health. This is indeed the case, with poor food 
appreciation and decreased appetite resulting in change in body weight (Croy et al., 2014). Aging individuals, and in particular the institutionalized, are considered especially vulnerable in this respect. Thus, researchers recognized decades ago that changes in chemosensory perception in aging are associated with poor food appreciation and appetite, change in food choice such as decreased dietary variation, poor nutritional status, change in body weight, and increased risk for chronic disease (Brown, 1976; Duffy \& Bartoshuk, 1996; Ferris \& Duffy, 1989; Griep et al., 1995; Mattes-Kulig \& Henkin, 1985; Schiffman \& Zervakis, 2002; D. A. Stevens \& Lawless, 1981; Wysocki \& Pelchat, 1993; however, see also Arganini \& Sinesio, 2015). A more recent study, using longitudinal data, strengthens the associations by showing that olfactory impairment in aging persons, at least among women, might be a contributing factor to poor diet quality (Gopinath et al., 2016). Furthermore, B. J. Rolls and McDermott (1991) demonstrated diminished sensory-specific satiety in old age, which may contribute to the decreased dietary variation with age, and Kremer et al. (2014) showed that those with diminished olfaction more often report eating the same meal within a week. However, not all studies have shown an association between chemosensory impairment and nutritional problems (e.g., Toussaint et al., 2015), and lack of sensory feedback from eating may in some cases actually lead the individual to eat more, increasing risk for obesity. There is also a considerable risk among aging adults to ingest spoiled food. It has, for example, been suggested that aging adults are less likely than young adults to reject foods with unpleasant odors (Pelchat, 2000). The unawareness of age-related olfactory loss (e.g., Nordin et al., 1995; Seubert et al., 2017) may aggravate the risk of ingesting spoiled food as these persons are less likely to take precautions to avoid eating such food.

How should these risks be mitigated? Early work by Schiffman et al. demonstrated that anorexia in the aging population may remit when foods are amplified by additional flavoring to compensate for diminished chemosensory function, resulting in increased preference for and intake of food, increased salivation, and improved immunological status and grip strength (Schiffman, 1998; Schiffman \& Miletic, 1999; Schiffman \& Warwick, 1988, 1993). However, in a recent review, Boesveldt et al. (2018) conclude that studies on flavor enhancement provide mixed results regarding its positive impact on food preference and intake among the aging adults. Because of the personal nature of food preferences and the heterogeneity of chemosensory decline in the aging population, flavor enhancement may not fit an individual's expectations or preferences (S. Koskinen et al., 2003). Future research on this topic should consider such individual differences; declining sensory abilities may interact with several other psychological and health-related variables that may moderate the risk for malnutrition and other harmful food behaviors. As the olfactory epithelium microbiome composition may be important for olfactory function and BMI, future work should assess whether it might play a causal role in whether olfactory abilities decline or are preserved in the aging process (K. Koskinen et al., 2018).

\section{Cognition and Dementia}

Olfactory deficits are a common feature of the normal aging processes but may also reflect unique patterns of cognitive brain changes in aging. To date, several studies have shown that olfactory deficits often coincide with or even precede impairments in nonolfactory cognitive tests (Djordjevic et al., 2008; Dulay \& Murphy, 2002; Swan \& Camelli, 2002; Wilson et al., 2006). Correlations between olfactory and cognitive deficits in aging adults are unlikely to arise simply due to the semantic memory components in the olfactory identification task. In fact, word knowledge is typically retained in old age, whereas odor identification declines 
(Larsson, Hedner, et al., 2009). Evidence from a large $(n=2,280)$ population-based sample of participants aged 60 to 100 years suggested that memory-based olfactory tests (odor recognition memory and identification) were differentiated from verbal episodic and semantic memory domains, and odor memory was best conceptualized as a distinct and separate factor in old age (Larsson et al., 2016). This outcome suggests that higher order olfactory functions have unique features relative to other types of declarative memory in old age. Indeed, the results favor the notion of a sensory system driven by its own premises, as exemplified by a poor language integration (Olofsson et al., 2014), low imagery capacity (Arshamian \& Larsson, 2014), and a higher emotionality relative other sensory modalities (Arshamian et al., 2013).

Prospective studies show that performance in odor identification could predict future decline in general cognition (Conti et al., 2013; Graves et al., 1999) or executive functioning (Schubert et al., 2013), and effects persist even after controlling for vocabulary, a nonolfactory control task where synonyms are matched (Olofsson, Larsson et al., 2020; Olofsson et al., 2009). These previous findings have recently been confirmed by a large-scale population-based study of middle-aged and aging participants (Tebrügge et al., 2018). Here, participants with olfactory deficits performed significantly worse on a large variety of cognitive subtests, such as verbal memory and fluency, problem solving, visuo-spatial abilities, speed of processing, and inhibition. According to some studies, the risk of future cognitive decline in aging individuals with olfactory loss depends on the ApoE gene; a plasma protein involved in lipid transport, and located on chromosome 19, carrying the three possible alleles $\varepsilon 2$, $\varepsilon 3$, and $\varepsilon 4$. The gene is expressed in the central nervous system (CNS), including the olfactory bulb and the olfactory epithelium (Nathan et al., 2007; Struble et al., 1999), and is believed to play a role in neuronal regenerative processes as well as in the development of Alzheimer's disease (AD). Aging ApoE $\& 4$ carriers with no sign of dementia have a diminished olfactory ability relative to noncarriers (Graves et al., 1999; Larsson et al., 2016; Olofsson et al., 2010), and in the $\varepsilon 4$ carrier group, olfactory deficits are more strongly indicative of generalized cognitive decline in the coming years (Olofsson, Larsson et al., 2020; Olofsson et al., 2009). Aging adults with an $\varepsilon 4$ allele also show a diminished electrophysiological brain activity in response to odors (Green et al., 2013). Despite some inconsistency in the literature (Handley et al., 2006), impaired odor identification has been observed in cognitively impaired aging $\varepsilon 4-$ carriers without dementia (Murphy et al., 1998). Longitudinal data suggest that aging $\varepsilon 4-$ carriers show larger-than-normal decline in odor identification performance (CalhounHaney \& Murphy, 2005; Josefsson et al., 2017). The accelerated decline concurs with declining episodic memory abilities (Josefsson et al., 2017). The main interpretation of these findings is that in the $\varepsilon 4$ carriers, olfactory dysfunction is predominantly caused by early, still preclinical AD pathology which accumulates in the mediotemporal lobe (Olofsson et al., 2016).

It was early demonstrated that pathology in AD encompasses olfactory brain areas as well as adjacent regions in the medial temporal lobes (e.g., Braak \& Braak, 1997). Moreover, poor performance on standardized olfactory tests correlates with dementia-related pathological markers in the brain of AD patients, such as with $t$-tau concentrations in cerebrospinal fluid (Reijs et al., 2017). Olfactory abilities are often correlated with those cognitive functions that typically decline in AD. Several prospective studies have suggested that olfactory loss might be particularly associated with future dysfunctions in tasks assessing episodic memory, which are early symptoms of AD (Finkel et al., 2011; Roberts et al., 2016; Swan \& Carmelli, 2002; Wilson et al., 2006). Accordingly, there is strong evidence for olfaction being markedly impaired in patients with AD (Devanand, 2018; Sun et al., 2012). A meta-analysis, including over 50 studies, showed that olfactory deficits were present in AD patients relative to 
controls in all included studies (Rahayel et al., 2012). Deficits in cognitively demanding olfactory tasks, such as identification and recognition memory, had higher effect sizes than deficits in olfactory detection sensitivity.

It has been proposed that olfactory deficits may be indicative of later conversion to AD. Although the exact cause of the disease remains elusive to this day, AD pathology such as $t$ tau and amyloid plaques are associated with neuronal loss and may affect the brain many years before a diagnosis can be given. The correct identification of individuals who are within the preclinical phase of dementia will be of key importance once successful methods to slow down disease progression are established. In recent years, a growing number of prospective research studies have focused on whether olfactory deficits may be predictive of later conversion to AD. Mild cognitive impairment (MCI) is a syndrome characterized by cognitive decline greater than can be expected based on a person's age and educational background, constituting a stage between normal cognitive aging and dementia (Gauthier et al., 2006). While the progression rate to AD is notably higher among patient groups with MCI, as compared with cognitively intact aging persons, not every person that has been diagnosed with MCI will eventually convert to dementia (Gauthier et al., 2006). MCI patients often perform poorly on olfactory tests (e.g., Goette et al., 2018; Palta et al., 2018), which raises the question if olfactory assessments can be used to predict whether an MCI patient will eventually develop dementia. In recent years, a handful of prospective longitudinal studies have therefore attempted to investigate the predictive role of olfactory testing for AD. All studies found significant associations between baseline odor identification ability in MCI and risk of later dementia progression (Conti et al., 2013; Devanand et al., 2008, 2015; Roberts et al., 2016). Devanand et al. (2008) estimated odor identification testing to have a sensitivity rate of almost $50 \%$ for predicting AD conversion within 3 years.

Apart from studying MCI patient groups, a few population-based studies have so far investigated the predictive utility of olfactory baseline ability on conversion to AD (Adams et al., 2018, Devanand et al., 2015; Stanciu et al., 2014; Yaffe et al., 2017). In these studies, a total of 7620 participants were followed longitudinally over an average follow-up time span of 94 months. The studies consistently found that poor olfactory identification predicted later progression to AD. All studies included follow-up analyses that controlled for the potentially confounding effects of demographic variables and baseline cognition, but the association between olfactory function and AD persisted. Stanciu et al. (2014) were the first to report a significant association between baseline odor identification performance and conversion to AD within 10 years in community-dwelling aging adults. Similar results were obtained by recent studies based on U.S. samples; effects are present in subsamples of Black and White persons, but the predictive effects are slightly weaker in the Black subgroup (Yaffe et al., 2017). Overall, poor odor identification is associated with conversion to AD within 2 to 10 years, with effect sizes that compare well to the standard AD biomarkers in MCI patients (Adams et al., 2018; Devanand et al., 2015). Although these group-level results are promising, it is important to note that such predictions are far from certain on the individual level. Most likely, this is because many aging persons have an olfactory impairment for reasons that are unrelated to dementia and which were described earlier. Thus, Devanand et al. (2020) recently suggested, based on empirical results from a large-scale longitudinal study, that olfaction should be used as a screening tool, such that aging persons with a high olfactory performance can be regarded as being at very low risk for dementia in the coming years, whereas a poor olfactory performance is less informative in terms of dementia risk (because olfactory impairment has many other potential causes), and further investigation is always needed before an increased risk of dementia can be established. 
Although this section has focused on MCI and AD, where olfactory impairments are closely linked to cognitive decline, olfactory loss is also prevalent in several other neurodegenerative disorders and dementia syndromes. After AD, vascular dementia (VaD) is a common cause. Nevertheless, studies about olfactory deficits in $\mathrm{VaD}$ are still relatively sparse. Although olfaction appears to be impaired in $\mathrm{VaD}$, mixed findings have been obtained regarding the magnitudes of these effects (Duff et al., 2002; Gray et al., 2001; Knupfer \& Spiegel, 1986). An explanation for this discrepancy has been proposed by Alves et al. (2014), who suggest that the extremity of an olfactory deficit may depend on the location and extent of vascular effects in the brain, which is highly variable among VaD patients. By contrast, olfactory dysfunction is among the earliest nonmotor symptom of Parkinsons' disease (PD) and is prevalent in approximately $90 \%$ of early stage PD cases (Doty, 2012). A meta-analysis comparing the effect of AD and PD on olfactory functions showed that both patient groups were more impaired in identification and recognition tasks than odor threshold tasks. However, PD showed larger impairments than AD patients in the detection task. This outcome suggests that persons with PD may be more impaired in sensory-driven tasks, whereas AD patients show larger impairments in higher order olfactory functions (Rahayel et al., 2012). In recent work, Lee et al. (2020) compared resting-state olfactory functional networks in PD and AD. Interestingly, comparisons showed that PD exhibited lower olfactory bulb connectivity with striatal-thalamic-frontal regions and lower orbitofrontal connectivity with striatal-frontal regions than AD. Overall, these pattern of findings are indicative of different neural mechanisms for smell dysfunction in PD and AD. In fronto-temporal dementia, a clinical spectrum that includes a variety of disorders, olfactory-cognitive (but not sensory) deficits are often observed alongside severe nonolfactory symptoms (Silva et al., 2019). The type of olfactory impairment depends largely on the location of cortical atrophy (Olofsson et al., 2013). The most well-established findings are the odor identification and naming deficits that co-occur with other semantic or associative deficits in patients with frontal or temporal lobe atrophy (Olofsson et al., 2013; Silva et al., 2019).

In summary, the results from recent prospective studies indicate that olfactory deficits may represent a promising candidate marker for preclinical AD, both in patient groups with MCI and in the general population of aging adults without an established cognitive impairment at baseline. Future studies are needed to investigate how early identification of AD may benefit from including olfactory assessments alongside other possible and established biomarkers. Of particular interest is to develop methods to rule out olfactory impairments due to other causes (e.g., postviral olfactory loss) in order to enhance the predictive utility of olfactory assessments.

\section{Mortality}

In the last decade, prospective studies indicate that olfactory deficits may be related to an elevated risk of mortality in aging persons. Wilson et al. (2011) found that the risk of death within an average time period of 4 years decreased by about $6 \%$ for each additional correct choice on an odor identification task. Similarly, Pinto et al. (2014) reported that anosmic individuals were more than 3 times as likely to die within 5 years as compared with normosic participants, even after statistically adjusting for numerous demographic, cognitive, and health variables. Gopinath et al. (2012) reported a similar association between olfactory deficits and risk of death. However, the results of their study also suggested the effect might be driven by participants who already had a cognitive impairment at baseline. An important emerging question has thus been whether the association between olfactory 
performance level and later mortality risk may be due to dementia conversion after baseline and before death at follow-up. While the three aforementioned studies were not able to account for dementia conversion, two recent large-scale population-based studies were able to analyze whether or not the association between olfactory deficits and mortality risk was driven by aging persons who converted to dementia after baseline and before death at follow-up. Devanand et al. (2015) followed 1,169 community-dwelling aging persons for a time span of approximately 5 years and found olfactory dysfunction to be predictive of a higher mortality risk even after statistically controlling for dementia conversion after baseline. Similar results were obtained by Ekström et al. (2017) in a sample of 1,774 middle-aged and aging adults in Sweden. The authors found olfactory deficits to emerge as a predictor of mortality risk during a time span of nearly 10 years, independently of dementia conversion between baseline and follow-up. Furthermore, the authors reported that the association between olfactory deficits and risk of mortality was present also in middle-aged adults who were younger than the participants in previous studies. These results recently received further empirical support in large-scale studies (Choi et al., 2020; Liu et al., 2019).

Taken together, these studies suggest that olfactory deficits may be related to an increased risk of mortality in both middle age and in aging. Of particular interest for future research is the mixed findings regarding dementia conversion, which does not account for the association between olfactory deficit and mortality in Ekström et al. (2017), but plays a role in some of the deaths in the research by Liu et al. (2019). Thus, the question of what exact mechanism (s) underlie the mortality-olfactory relationship remains unresolved. In some individuals, an olfactory deficit may pose a lethal hazard, as it may increase the risk of accidents at home, such as gas poisonings and the consumption of spoiled foods (Bonfils et al., 2008; Doty \& Kamath, 2014; Santos et al., 2004). However, it is unlikely that olfactory-related accidents, a relatively rare cause of death among aging persons, may emerge as a main explanation. Furthermore, malnutrition caused by olfactory loss may lead to increased risk of death, although this explanation has not received empirical support thus far (Pinto et al., 2014).

An alternative explanation is that the olfactory system may be particularly exposed to the effects of aging and disease as it relies on cellular regeneration (Pagano et al., 2000), a process that has been associated with age-related impairment (Laws et al., 2002; Striepens et al., 2011; Watabe-Rudolph et al., 2011). Furthermore, the olfactory system is unique among sensory systems in being directly exposed to the environment. As such, it may be sensitive to accumulative damage caused by environmental hazards (Doty, 2008). Thus, rather than causing death per se, olfactory performance may be indicative of fundamental physiological processes of aging in the CNS and their interactions with environmental exposures (Pinto et al., 2014). As a consequence, the state of the olfactory system may be sensitive to a variety of health issues that might increase mortality risk. More research is needed to establish these mechanisms in more detail (Van Regemorter et al., 2020).

\section{Environment and Genetics}

Fundamental to our understanding of age-related olfactory changes is the interplay between environment and genetics. Research on the heritability of olfactory functions suggest that olfactory abilities do not have a strong heritability component, and that most variation can be attributed to the environment (Doty et al., 2011; Finkel et al., 2001). Although odor identification has a modest heritability, due to its partial reliance on overall cognition (Finkel et al., 2001), aging individuals show a low heritability, suggesting environmental effects are paramount. Among the environmental effects on olfaction in old age, medical conditions and medication are among the most important. Doty (2008) listed over 200 
etiologies that, irrespective of age, can cause an olfactory disorder. The mechanisms underlying these disorders can be classified as conductive (e.g., caused by nasal polyposis), sensorineural (e.g., postviral upper respiratory infection), or impairment in the olfactory CNS (e.g., tumor). The most common etiologies of olfactory disorders among patients seeking medical attention at ear, nose, and throat clinics include upper respiratory infection, chronic sinusitis, nasal polyposis, allergic rhinitis, and head trauma (Brämerson et al., 2007; Temmel et al., 2002). The presence of type-2 diabetes accelerates age-related olfactory decline (Ekström et al., 2020; Olofsson et al., 2010). Given the profound impact of such conditions on the olfactory system, it is not surprising that environmental variables overshadow genetic variables in their effects of olfactory abilities among aging individuals (Doty \& Kamath, 2014; Rawson, 2006).

Medication is an environmentally related factor of particular relevance in the context of olfaction and aging. Results from the United States suggests that adults over 65 years of age take on average about three to four medications and institutionalized aging persons take about twice as many (Finkelstein \& Schiffman, 1999). It has been suggested that more than 250 drugs may alter smell and taste sensations. These include antihistamines, lipid-lowering drugs, antimicrobial medications, antineoplastic medications, asthma medications, antihypertensives, muscle relaxants, and antidepressants (Schiffman, 1991). Nutritional deficits, such as reduced levels of zinc and vitamin A and B, are known to affect sensitivity and hedonics of taste and smell (Aliani et al., 2013; Schiffman, 1997). The effects of malnutrition on chemosensory perception may, in turn, affect food intake and aggravate the state of malnutrition. Poor oral health in aging persons, such as tooth loss and caries, may affect retronasal olfactory perception and provides an additional challenge (Seiberling \& Conley, 2004; Ship, 1999; Solemdal et al., 2012).

Long-term exposure to environmental pollutants, such as air pollution, may constitute a key environmental variable in age-related olfactory decline. Microscopic airborne pollutants can bypass the blood-brain barrier via the olfactory nerves, where they may initiate inflammation (Block \& Calderón-Garcidueñas, 2009; Lucchini et al., 2012; Oberdörster et al., 2004). It has therefore been proposed that exposure to airborne pollutants may affect olfactory function in aging adults for whom xenobiotic exposure has accumulated over a longer time (Doty \& Kamath, 2014). Indeed, one study has so far found significant associations between exposure to the fine particulate matter $\left(\mathrm{PM}_{2.5}\right.$, diameter $\left.<2.5 \mu \mathrm{m}\right)$ and worse olfactory identification scores among community-dwelling aging adults (Ajmani, Suh, Wroblewski, et al., 2016). These findings are corroborated by studies based on proxies for pollutant exposures (Ajmani, Suh, \& Pinto, et al., 2016; Calderón-Garcidueñas et al., 2010; Hudson et al., 2006; Ranft et al., 2009).

In the last few years, researchers have begun to investigate olfactory abilities using genome-wide associations. Human olfactory receptor genes are characterized by high levels of genetic inactivation and variability, which might lead to highly variable odor percepts (Mainland et al., 2014). Indeed, Gisladottir et al. (2020) recently found that the intensity and nameability of individual food-associated odors such as trimethylamine (fish odor), trans-anethole (liqorice odor), and trans-cinnamaldehyde (cinnamon odor) might vary in the population due to genetic influences on olfactory receptors. Although these results highlight some ways by which human genetic variability might shape olfactory abilities, their implications for aging are less well known. There is still little work done on gene-environment interactions from an aging perspective, for example, how genetics might make certain aging individuals more vulnerable to olfactory deficits as a function of medication, less able to recover from post-viral anosmia, or other common causes of age-related olfactory loss. Such 
approaches would, however, be beneficial for our basic understanding of the aging olfactory system, and they might have clinical usefulness.

\section{Training-Based Enhancement}

The olfactory decline observed in aging may seem irreversible. But emerging evidence suggests that olfactory performance may in fact be trained. Most olfactory training studies to date have focused on patients with severe olfactory loss following a viral infection or other causes, and the studies have involved a simple training protocol where a set of odors are smelled twice daily (Hummel et al., 2009). Participants in these studies are usually of middle age or aging, and many appear to benefit from the olfactory training regime relative to a control group that might experience spontaneous recovery but no training effect (Damm et al., 2014). One study suggested that the benefits of olfactory training extend to nonolfactory health-associated variables; after olfactory training, participants reported feeling younger than before training (Wegener et al., 2017). The study also reported cognitive performance benefits of olfactory training, but this interaction effect was driven by poorer baseline performance of the olfactory training group so it needs replication before conclusions can be drawn about cognitive effects. Indeed, if olfactory training leads to cognitive benefits, what are the mechanisms? While only a few research reports have addressed cortical changes related to olfactory training, they have yielded promising results in young adults. A study on cortical thickness suggested that olfactory training led to increased thickness not only in key olfactory structures but also in fronto-temporal areas outside of the olfactory cortex (Al Aïn et al., 2019). A similar study on odor identification training showed functional brain activity changes in a fronto-parietal network associated with higher cognitive abilities (Fournel et al., 2017). Connectivity analysis might provide a further understanding of how dynamic cortical networks are modulated by repeated olfactory task engagement and how they might underlie behavioral changes (Reichert \& Schöpf, 2018). The results so far are promising, but further research should focus on achieving high-powered studies with aging participants, who might be less susceptible than young adults to training effects.

The notion that olfactory training has potential to not only help recovery from age-related olfactory loss but also boost cognitive and emotional health of aging participants is exciting. However, to substantiate claims of cognitive and health-related effects, we argue that researchers should adopt more sophisticated training paradigms and pinpoint the biological mechanisms that may mediate generalizable benefits of olfactory training. Well-calibrated nonolfactory control conditions and rigorous assessment of transfer properties from olfactory training to nonolfactory cognitive benefits are often lacking. While new methods are emerging, as discussed earlier, the standard olfactory training methodology involves merely a focused smelling and does not try to engage olfactory-cognitive processes. The olfactory exposure is thus relatively passive in comparison to typical visual cognitive "brain training" training paradigms. Furthermore, the standard olfactory task is not behaviorally wellcharacterized as no precise behavioral data are collected during the training period, which might last for over 6 months. Little is known about how participants engage with the odors during training, and this limits our understanding of the training effect. For this reason, we have developed new methods for olfactory training that may facilitate research progress in this area. We recently developed a smell memory game that involves finding 12 matching pairs among a set of 24 stimuli in as few trials as possible (Olofsson et al., 2020). Healthy adult participants were randomized to train either their smell memory using tea flavors, or visual memory using Asian language symbols, for 40 days. Results showed that olfactory training, but not visual training, leads to improvements in odor discrimination and naming, 
as assessed with the Sniffin sticks olfactory assessment. The performance increase put the participants at the same level as a group of wine experts. Furthermore, we found that olfactory training led to performance increase in the visual task (i.e., cross-sensory transfer), whereas no corresponding benefit was observed in the olfactory task from visual memory training (Olofsson, Ekström et al., 2020). This task allows for assessing and logging performance at each training occasion. Game-like tasks might become a useful mode of training, especially for aging individuals who have retained some olfactory sensitivity, but who wish to use olfactory training to improve further, or to yield possible cognitive or emotional benefits. Ongoing efforts include assessing how well the smell memory training paradigm works in aging participants and how training may lead to performance and cortical changes in this group, and computerized versions of this task that enable laboratory testing of how cortical processing changes mediate performance changes. A further development which might accelerate olfactory training research is innovative hardware and software solutions for computerized olfactory training. Computerized odor interactions may allow for more precise behavioral assessment, game-like interfaces with adaptive difficulty level and feedback that increases motivation. These features can be used to facilitate user engagement and rehabilitation. Toward this goal, we are developing hand-held olfactometers for Virtual Reality applications (Niedenthal et al., 2019), as well as simpler olfactory hardware solutions that can be used to run olfactory training and assessment on a laptop computer (Niedenthal et al., 2021). Olfactory deficit is a common consequence of coronavirus infection and has recently received increasing attention. As aging adults are dysproportionately affected by the virus and olfactory abilities are already fragile in many aging persons, the coronavirus might have long-lasting and detrimental effects on olfaction in the aging population. Improving olfactory training methodology is challenging because of the compound difficulties of studying olfaction remotely, and of randomized controlled trials, but these challenges need to be met in order for the field to move forward (Pekala et al., 2016).

\section{Conclusion}

Much progress has been made in understanding olfactory impairments in aging. Although these impairments arise from a multitude of factors, they are not unavoidable. We argue that future research challenges appear at the intersection of biology and behavior and should aim at reversing olfactory impairments and its health-associated outcomes in aging individuals whenever possible. Health-related consequences of olfactory loss are heterogeneous, and little is still known about individual differences that determine outcomes such as malnutrition. Olfactory loss is a well-established risk factor for dementia and cognitive decline in aging individuals. Here, optimizing the predictive utility of olfactory tests for dementia, with a special focus on how to rule out more benign causes of olfactory loss, remains an issue of critical importance. Olfactory loss has also emerged as a predictor of mortality risk, but little is still known about the underlying mechanisms, and to what extent dementia is a mediating factor that explains the association between olfactory loss and mortality. Given the wideranging health aspects of olfactory loss, it is critical to develop effective treatments for olfactory loss. Smell training offers a set of noninvasive methods by which olfactory exposure may benefit olfaction and perhaps also health and cognition. Future research may explore the many possible benefits of smell training; however, this line of research will benefit from improved methodologies using computer-based assessments and other innovations for improving transparency, compliance, effectiveness, and precision. Research on olfactory genetics has led to an appreciation for the diversity and individual differences in olfactory receptor biology, but we still have a limited understanding of how these genetic variables 
may have different effects in aging individuals and how genetic effects shape our resilience to environmental effects that accumulate over the lifespan. In sum, understanding how olfactory abilities are diminished and how they may perhaps be alleviated or recovered in old age presents a set of challenging tasks for researchers in the years to come.

\section{Acknowledgements}

The authors thank Teodor Jernsäther for valuable assistance.

\section{Declaration of Conflicting Interests}

The author(s) declared no potential conflicts of interest with respect to the research, authorship, and/or publication of this article.

\section{Funding}

The author(s) disclosed receipt of the following financial support for the research, authorship, and/or publication of this article: This work was supported by grants from the Swedish Foundation for Humanities and Social Sciences (M14-0375:1) to M. L. and Knut \& Alice Wallenberg Foundation (2016:0229) to J. K. O.

\section{ORCID iD}

Jonas K. Olofsson (D) https://orcid.org/0000-0002-0856-0569

\section{References}

Adams, D. R., Kern, D. W., Wroblewski, K. E., McClintock, M. K., Dale, W., \& Pinto, J. M. (2018). Olfactory dysfunction predicts subsequent dementia in older U.S. adults. Journal of the American Geriatrics Society, 66(1), 140-144. https://doi.org/10.1111/jgs.15048

Ajmani, G. S., Suh, H. H., \& Pinto, J. M. (2016). Effects of ambient air pollution exposure on olfaction: A review. Environmental Health Perspectives, 124(11), 1683-1693. https://doi.org/10.1289/ehp136

Ajmani, G. S., Suh, H. H., Wroblewski, K. E., Kern, D. W., Schumm, L. P., McClintock, M. K., Yanosky, J. D., \& Pinto, J. M. (2016). Fine particulate matter exposure and olfactory dysfunction among urban-dwelling older US adults. Environmental Research, 151, 797-803. https://doi.org/10. 1016/j.envres.2016.09.012

Al Aïn, S., Poupon, D., Hétu, S., Mercier, N., Steffener, J., \& Frasnelli, J. (2019). Smell training improves olfactory function and alters brain structure. NeuroImage, 189, 45-54. https://doi.org/ 10.1016/j.neuroimage.2019.01.008

Aliani, M., Udenigwe, C. C., Girgih, A. T., Pownall, T. L., Bugera, J. L., \& Eskin, M. N. A. (2013). Zinc deficiency and taste perception in the elderly. Critical Reviews in Food Science and Nutrition, 53(3), 245-250. https://doi.org/10.1080/10408398.2010.527023

Alves, J., Petrosyan, A., \& Magalhães, R. (2014). Olfactory dysfunction in dementia. World Journal of Clinical Cases: WJCC, 2(11), 661. https://doi.org/10.12998/wjcc.v2.i11.661

Arganini, C., \& Sinesio, F. (2015). Chemosensory impairment does not diminish eating pleasure and appetite in independently living older adults. Maturitas, 82(2), 241-244. https://doi.org/10.1016/j. maturitas.2015.07.015

Arshamian, A., Iannilli, E., Gerber, J. C., Willander, J., Persson, J., Seo, H. S., Hummel, T., \& Larsson, M. (2013). The functional neuroanatomy of odor evoked autobiographical memories cued by odors and words. Neuropsychologia, 51(1), 123-131. https://doi.org/10.1016/j.neuropsychologia. 2012.10.023

Arshamian, A., \& Larsson, M. (2014). Same same but different: The case of olfactory imagery. Frontiers in Psychology, 5, 34. https://doi.org/10.3389/fpsyg.2014.00034

Attems, J., Walker, L., \& Jellinger, K. A. (2015). Olfaction and aging: A mini-review. Gerontology, 61(6), 485-490. https://doi.org/10.1159/000381619 
Bahar-Fuchs, A., Moss, S., Rowe, C., \& Savage, G. (2011). Awareness of olfactory deficits in healthy aging, amnestic mild cognitive impairment and Alzheimer's disease. International Psychogeriatrics, 23(7), 1097-1106. https://doi.org/10.1017/s1041610210002371

Birch, L. L., \& Deysher, M. (1986). Caloric compensation and sensory specific satiety: Evidence for self regulation of food intake by young children. Appetite, 7(4), 323-331. https://doi.org/10.1016/s01956663(86)80001-0

Block, M. L., \& Calderón-Garcidueñas, L. (2009). Air pollution: mechanisms of neuroinflammation and CNS disease. Trends in neurosciences, 32(9), 506-516. https://doi.org/10.1016/j.tins.2009.05.009

Boesveldt, S., Bobowski, N., McCrickerd, K., Maître, I., Sulmont-Rossé, C., \& Forde, C. G. (2018). The changing role of the senses in food choice and food intake across the lifespan. Food Quality and Preference, 68, 80-89. https://doi.org/10.1016/j.foodqual.2018.02.004

Boesveldt, S., \& de Graaf, K. (2017). The differential role of smell and taste for eating behavior. Perception, 46(3-4), 307-319. https://doi.org/10.1177/0301006616685576

Boesveldt, S., Postma, E. M., Boak, D., Welge-Luessen, A., Schöpf, V., Mainland, J. D., Martens, J., Ngai, J., \& Duffy, V. B. (2017). Anosmia-A clinical review. Chemical Senses, 42(7), 513-523. https://doi.org/10.1093/chemse/bjx025

Boesveldt, S., Yee, J. R., McClintock, M. K., \& Lundström, J. N. (2017). Olfactory function and the social lives of older adults: A matter of sex. Scientific Reports, 7(1), 45118. https://doi.org/10.1038/ srep45118

Bonfils, P., Faulcon, P., Tavernier, L., Bonfils, N. A., \& Malinvaud, D. (2008). Accidents domestiques chez 57 patients ayant une perte sévère de l'odorat [Home accidents associated with anosmia]. Presse medicale (Paris, France0: 1983), 37(5 Pt 1), 742-745. https://doi.org/10.1016/j.lpm.2007.09.028

Braak, H., \& Braak, E. (1997). Frequency of stages of Alzheimer-related lesions in different age categories. Neurobiology of Aging, 18(4), 351-357. https://doi.org/10.1016/s0197-4580(97)00056-0

Brämerson, A., Johansson, L., Ek, L., Nordin, S., \& Bende, M. (2004). Prevalence of olfactory dysfunction: The Skövde population-based study. The Laryngoscope, 114(4), 733-737. https://doi.org/ 10.1097/00005537-200404000-00026

Brämerson, A., Nordin, S., \& Bende, M. (2007). Clinical experience with patients with olfactory complaints, and their quality of life. Acta Oto-Laryngologica, 127(2), 167-174. https://doi.org/10. $1080 / 00016480600801357$

Brown, E. L. (1976). Factors influencing food choices in the elderly. Geriatrics, 31, 89-92.

Brownie, S. (2006). Why are elderly individuals at risk of nutritional deficiency? International Journal of Nursing Practice, 12(2), 110-118. https://doi.org/10.1111/j.1440-172x.2006.00557.x

Cain, W. S., de Wijk, R. A., Nordin, S., \& Nordin, M. (2008). Independence of odor quality and absolute sensitivity in a study of aging. Chemosensory Perception, 1(1), 24-33. https://doi.org/10. 1007/s12078-007-9002-0

Cain, W. S., Reid, F., \& Stevens, J. C. (1990). Missing ingredients: Aging and the discrimination of flavor. Journal of Nutrition for the Elderly, 9(3), 3-15. https://doi.org/10.1300/j052v09n03_02

Calderón-Garcidueñas, L., Franco-Lira, M., Henríquez-Roldán, C., Osnaya, N., González-Maciel, A., Reynoso-Robles, R., Villarreal-Calderon, R., Herritt, L., Brooks, D., Keefe, S., Palacios-Moreno, J., Villarreal-Calderon, R., Torres-Jardón, R., Medina-Cortina, H., Delgado-Chávez, R., AielloMora, M., Maronpot, R. R., \& Doty, R. L. (2010). Urban air pollution: Influences on olfactory function and pathology in exposed children and young adults. Experimental and Toxicologic Pathology, 62(1), 91-102. https://doi.org/10.1016/j.etp.2009.02.117

Calhoun-Haney, R., \& Murphy, C. (2005). Apolipoprotein $\varepsilon 4$ is associated with more rapid decline in odor identification than in odor threshold or Dementia Rating Scale scores. Brain and Cognition, 58(2), 178-182. https://doi.org/10.1016/j.bandc.2004.10.004

Cerf-Ducastel, B., \& Murphy, C. (2003). FMRI brain activation in response to odors is reduced in primary olfactory areas of elderly subjects. Brain Research, 986(1-2), 39-53. https://doi.org/10.1016/ s0006-8993(03)03168-8

Choi, J. S., Hur, K., Chow, M., Shen, J., \& Wrobel, B. (2018). Olfactory dysfunction and cognition among older adults in the United States. International Forum of Allergy \& Rhinology, 8(5), 648-654. https://doi.org/10.1002/alr.22078 
Choi, J. S., Jang, S. S., Kim, J., Hur, K., Ference, E., \& Wrobel, B. (2020). Association between olfactory dysfunction and mortality in US adults. JAMA Otolaryngology-Head \& Neck Surgery. Advance online publication. https://doi.org/10.1001/jamaoto.2020.3502

Choudhury, E. S., Moberg, P., \& Doty, R. L. (2003). Influences of age and sex on a microencapsulated odor memory test. Chemical Senses, 28(9), 799-805. https://doi.org/10.1093/chemse/bjg072

Conti, M. Z., Vicini-Chilovi, B., Riva, M., Zanetti, M., Liberini, P., Padovani, A., \& Rozzini, L. (2013). Odor identification deficit predicts clinical conversion from mild cognitive impairment to dementia due to Alzheimer's disease. Archives of clinical neuropsychology: the official journal of the National Academy of Neuropsychologists, 28(5), 391-399. https://doi.org/10.1093/arclin/act032

Croy, I., Nordin, S., \& Hummel, T. (2014). Olfactory disorders and quality of life-An updated review. Chemical Senses, 39(3), 185-194. https://doi.org/10.1093/chemse/bjt072

Damm, M., Pikart, L. K., Reimann, H., Burkert, S., Göktas, Ö., Haxel, B., Frey, S., Charalampakis, I., Beule, A., Renner, B., Hummel, T., \& Hüttenbrink, K-B. (2014). Olfactory training is helpful in postinfectious olfactory loss: A randomized, controlled, multicenter study. The Laryngoscope, 124(4), 826-831. https://doi.org/10.1002/lary.24340

Davis, J. D., \& Levine, M. W. (1977). A model for the control of ingestion. Psychological Review, 84(4), 379-412.

de Graaf, C., Polet, P., \& van Staveren, W. A. (1994). Sensory perception and pleasantness of food flavors in elderly subjects. Journal of gerontology, 49(3), P93-P99. https://doi.org/10.1093/geronj/49. 3.p93

De Houwer, J., Thomas, S., \& Baeyens, F. (2001). Associative learning of likes and dislikes: A review of 25 years of research on human evaluative conditioning. Psychological Bulletin, 127(6), 853-869. https://doi.org/10.1037/0033-2909.127.6.853

de Wijk, R.A., \& Cain, W.S. (1994). Odor quality: Discrimination versus free and cued identification. Perception \& Psychophysics, 56, 12-18. https://doi.org/10.3758/BF03211686

Devanand, D. P. (2018). Impaired identification of specific odors and cognition in older adults. The American Journal of Geriatric Psychiatry, 26(8), 847-848. https://doi.org/10.1016/j.jagp.2018.03.009

Devanand, D. P., Lee, S., Luchsinger, J. A., Andrews, H., Goldberg, T., Huey, E. D., Schupf, N., Manly, J., Stern, Y., Kreisl, W. C., \& Mayeux, R. (2020). Intact global cognitive and olfactory ability predicts lack of transition to dementia. Alzheimer's \& Dementia, 16(2), 326-334. https://doi. org/10.1016/j.jalz.2019.08.200

Devanand, D. P., Lee, S., Manly, J., Andrews, H., Schupf, N., Doty, R. L., Stern, Y., Zahodne, L. B., Louis, E. D., \& Mayeux, R. (2015). Olfactory deficits predict cognitive decline and Alzheimer dementia in an urban community. Neurology, 84(2), 182-189. https://doi.org/10.1212/wnl. 000000000001132

Devanand, D. P., Liu, X., Tabert, M. H., Pradhaban, G., Cuasay, K., Bell, K., de Leon, M. J., Doty, R. L., Stern, Y., \& Pelton, G. H. (2008). Combining Early Markers Strongly Predicts Conversion from Mild Cognitive Impairment to Alzheimer's Disease. Biological Psychiatry, 64(10), 871-879. https://doi.org/10.1016/j.biopsych.2008.06.020

Djordjevic, J., Jones-Gotman, M., De Sousa, K., \& Chertkow, H. (2008). Olfaction in patients with mild cognitive impairment and Alzheimer's disease. Neurobiology of Aging, 29(5), 693-706. https:// doi-org.ezp.sub.su.se/10.1016/j.neurobiolaging.2006.11.014

Donini, L. M., Savina, C., \& Cannella, C. (2003). Eating habits and appetite control in the elderly: The anorexia of aging. International Psychogeriatrics, 15(1), 73-87. https://doi.org/10.1017/ s1041610203008779

Doty, R. L. (2008). The olfactory vector hypothesis of neurodegenerative disease: Is it viable? Annals of Neurology, 63(1), 7-15. https://doi.org/10.1002/ana.21327

Doty, R. L., Shah, M., \& Bromley, S. M. (2008). Drug-induced taste disorders. Drug safety, 31(3), 199215. https://doi.org/10.2165/00002018-200831030-00002

Doty R. L. (2012). Olfactory dysfunction in Parkinson disease. Nature Reviews. Neurology, 8(6), 329-339. https://doi.org/10.1038/nrneurol.2012.80

Doty, R. L., \& Kamath, V. (2014). The influences of age on olfaction: A review. Frontiers in Psychology, 5, 1-20. https://doi.org/10.3389/fpsyg.2014.00020 
Doty, R. L., Petersen, I., Mensah, N., \& Christensen, K. (2011). Genetic and environmental influences on odor identification ability in the very old. Psychology and Aging, 26(4), 864-871. https://doi.org/ $10.1037 / \mathrm{a} 0023263$

Doty, R. L., Shaman, P., Applebaum, S. L., Giberson, R., Siksorski, L., \& Rosenberg, L. (1984). Smell identification ability: Changes with age. Science (New York, N.Y.), 226(4681), 1441-1443. https:// doi.org/10.1126/science. 6505700

Duff, K., McCaffrey, R. J., \& Solomon, G. S. (2002). The Pocket Smell Test: Successfully discriminating probable Alzheimer's dementia from vascular dementia and major depression. The Journal of Neuropsychiatry and Clinical Neurosciences, 14(2), 197-201. https://doi.org/10.1176/jnp.14.2.197

Duffy, V. B., \& Bartoshuk, L. M. (1996), Sensory factors in feeding. In E. D. Capaldi (Ed.), Why we eat what we eat: The psychology of eating (1st ed., pp. 145-171). American Psychological Association.

Duffy, V. B., Cain, W. S., \& Ferris, A. (1999). Measurement of sensitivity to olfactory flavor: Application in a study of aging and dentures. Chemical Senses, 24(6), 671. https://doi.org/10. 1093/chemse/24.6.671

Dulay, M. F., \& Murphy, C. (2002). Olfactory acuity and cognitive function converge in older adulthood: support for the common cause hypothesis. Psychology and aging, 17(3), 392-404.

Ekström, I., Josefsson, M., Larsson, M., Rönnlund, M., Nordin, S., \& Olofsson, J. K. (2019). Subjective olfactory loss in older adults concurs with long-term odor identification decline. Chemical Senses, 44(2), 105-112. https://doi.org/10.1093/chemse/bjy079

Ekström, I., Larsson, M., Rizzuto, D., Fastbom, J., Bäckman, L., \& Laukka, E. J. (2020). Predictors of olfactory decline in aging: A longitudinal population-based study. The Journals of Gerontology: Series A. Advance online publication. https://doi.org/10.1093/gerona/glaa221

Ekström, I., Sjölund, S., Nordin, S., Nordin Adolfsson, A., Adolfsson, R., Nilsson, L. G., Larsson, M., \& Olofsson, J. K. (2017). Smell Loss Predicts Mortality Risk Regardless of Dementia Conversion. Journal of the American Geriatrics Society, 65(6), 1238-1243. https://doi.org/10.1111/jgs.14770

Ferris, A. M., \& Duffy, V. B. (1989). Effect of olfactory deficits on nutritional status: Does age predict persons at risk? Annals of the New York Academy of Sciences, 561(1), 113-123. https://doi.org/10. 1111/j.1749-6632.1989.tb20975.x

Finkel, D., Pedersen, N. L., \& Larsson, M. (2001). Olfactory functioning and cognitive abilities: A twin study. The Journals of Gerontology Series B: Psychological Sciences and Social Sciences, 56(4), P226-P233. https://doi.org/10.1093/geronb/56.4.p226

Finkel, D., Reynolds, C. A., Larsson, M., Gatz, M., \& Pedersen, N. L. (2011). Both odor identification and ApoE- $\varepsilon 4$ contribute to normative cognitive aging. Psychology and aging, 26(4), 872-883. https:// doi.org/10.1037/a0023371

Finkelstein, J. A., \& Schiffman, S. S. (1999). Workshop on taste and smell in the elderly: An overview. Physiology \& Behavior, 66(2), 173-176. https://doi.org/10.1016/s0031-9384(98)00261-3

Fournel, A., Sezille, C., Licon, C. C., Sinding, C., Gerber, J., Ferdenzi, C., Hummel, T., \& Bensafi, M. (2017). Learning to name smells increases activity in heteromodal semantic areas. Human Brain Mapping, 38(12), 5958-5969. https://doi.org/10.1002/hbm.23801

Gauthier, S., Reisberg, B., Zaudig, M., Petersen, R. C., Ritchie, K., Broich, K., Belleville, S., Brodaty, H., Bennett, D., Chertkow, H., Cummings, J. L., de Leon, M., Feldman, H., Ganguli, M., Hampel, H., Scheltens, P., Tierney, M. C., Whitehouse, P., Winblad, B., \& International Psychogeriatric Association Expert Conference on mild cognitive impairment (2006). Mild cognitive impairment. Lancet (London, England), 367(9518), 1262-1270. https://doi.org/10.1016/S0140-6736(06)68542-5

Gisladottir, R. S., Ivarsdottir, E. V., Helgason, A., Jonsson, L., Hannesdottir, N. K., Rutsdottir, G., Arnadottir, G. A., Skuladottir, A., Jonsson, B. A., Norddahl, G. L., Ulfarsson, M. O., Helgason, H., Halldorsson, B. V., Nawaz, M. S., Tragante, V., Sveinbjornsson, G., Thorgeirsson, T., Oddsson, A., Kristjansson, R. P., ... Stefansson, K. (2020). Sequence variants in TAAR5 and other loci affect human odor perception and naming. Current Biology, 30, 1-11. https://doi.org/10.1016/j.cub.2020. 09.012

Goette, W. F., Werry, A. E., \& Schmitt, A. L. (2018). The relationship between smell identification and neuropsychological domains: Results from a sample of community-dwelling adults suspected of 
dementia. Journal of Clinical and Experimental Neuropsychology, 40(6), 595-605. https://doi.org/10. $1080 / 13803395.2017 .1399985$

Gopinath, B., Anstey, K. J., Kifley, A., \& Mitchell, P. (2012). Olfactory impairment is associated with functional disability and reduced independence among older adults. Maturitas, 72(1), 50-55. https:// doi.org/10.1016/j.maturitas.2012.01.009

Gopinath, B., Russell, J., Sue, C. M., Flood, V. M., Burlutsky, G., \& Mitchell, P. (2016). Olfactory impairment in older adults is associated with poorer diet quality over 5 years. European Journal of Nutrition, 55(3), 1081-1087. https://doi.org/10.1007/s00394-015-0921-2

Graves, A. B., Bowen, J. D., Rajaram, L., McCormick, W. C., McCurry, S. M., Schellenberg, G. D., \& Larson, E. B. (1999). Impaired olfaction as a marker for cognitive decline: interaction with apolipoprotein E epsilon4 status. Neurology, 53(7), 1480-1487. https://doi-org.ezp.sub.su.se/10.1212/wnl. 53.7.1480

Gray, A. J., Staples, V., Murren, K., Dhariwal, A., \& Bentham, P. (2001). Olfactory identification is impaired in clinic-based patients with vascular dementia and senile dementia of Alzheimer type. International Journal of Geriatric Psychiatry, 16(5), 513-517. https://doi.org/10.1002/gps.383

Green, A. J., Cervantez, M., Graves, L. V., Morgan, C. D., \& Murphy, C. (2013). Age and apolipoprotein E $\varepsilon 4$ effects on neural correlates of odor memory. Behavioral Neuroscience, 127(3), 339-349. https://doi.org/10.1037/a0031891

Griep, M. I., Mets, T. F., Vercruysse, A., Cromphout, I., Ponjaert, I., Toft, J., \& Massart, D. L. (1995). Food odor thresholds in relation to age, nutritional, and health status. The Journals of Gerontology Series A: Biological Sciences and Medical Sciences, 50(6), B407-B414. https://doi.org/10.1093/ gerona/50a.6.b407

Handley, O. J., Morrison, C. M., Miles, C., \& Bayer, A. J. (2006). ApoE gene and familial risk of Alzheimer's disease as predictors of odour identification in older adults. Neurobiology of Aging, 27(10), 1425-1430. https://doi.org/10.1016/j.neurobiolaging.2005.08.001

Hedner, M., Larsson, M., Arnold, N., Zucco, G. M., \& Hummel, T. (2010). Cognitive factors in odor detection, odor discrimination, and odor identification tasks. Journal of Clinical and Experimental Neuropsychology, 32(10), 1062-1067. https://doi.org/10.1080/13803391003683070

Hoffman, H. J., Rawal, S., Li, C.-M., \& Duffy, V. B. (2016). New chemosensory component in the U.S. National Health and Nutrition Examination Survey (NHANES): First-year results for measured olfactory dysfunction. Reviews in Endocrine and Metabolic Disorders, 17(2), 221-240. https://doi. org/10.1007/s11154-016-9364-1

Hudson, R., Arriola, A., Martínez-Gómez, M., \& Distel, H. (2006). Effect of air pollution on olfactory function in residents of Mexico City. Chemical Senses, 31(1), 79-85. https://doi.org/10.1093/chemse/ bjj019

Hummel, T., Rissom, K., Reden, J., Hähner, A., Weidenbecher, M., \& Hüttenbrink, K.-B. (2009). Effects of olfactory training in patients with olfactory loss. The Laryngoscope, 119(3), 496-499. https://doi.org/10.1002/lary.20101

Hummel, T., Sekinger, B., Wolf, S. R., Pauli, E., \& Kobal, G. (1997). 'Sniffin' sticks': Olfactory performance assessed by the combined testing of odour identification, odor discrimination and olfactory threshold. Chemical Senses, 22(1), 39-52. https://doi.org/10.1093/chemse/22.1.39

Josefsson, M., Larsson, M., Nordin, S., Adolfsson, R., \& Olofsson, J. (2017). APOE-ع4 effects on longitudinal decline in olfactory and non-olfactory cognitive abilities in middle-aged and old adults. Scientific Reports, 7(1), 1286. https://doi.org/10.1038/s41598-017-01508-7

Kaneda, H., Maeshima, K., Goto, N., Kobayakawa, T., Ayabe-Kanamura, S., \& Saito, S. (2000). Decline in taste and odor discrimination abilities with age, and relationship between gustation and olfaction. Chemical Senses, 25(3), 331-337. https://doi.org/10.1093/chemse/25.3.331

Kern, D. W., Wroblewski, K. E., Schumm, L. P., Pinto, J. M., Chen, R. C., \& McClintock, M. K. (2014). Olfactory function in wave 2 of the National Social Life, Health, and Aging Project. The Journals of Gerontology Series B: Psychological Sciences and Social Sciences, 69(Suppl 2), S134-S143. https://doi.org/10.1093/geronb/gbu093 
Knupfer, L., \& Spiegel, R. (1986). Differences in olfactory test performance between normal aged, Alzheimer and vascular type dementia individuals. International Journal of Geriatric Psychiatry, 1(1), 3-14. https://doi.org/10.1002/gps.930010103

Koskinen, K., Reichert, J. L., Hoier, S., Schachenreiter, J., Duller, S., Moissl-Eichinger, C., \& Schöpf, V. (2018). The nasal microbiome mirrors and potentially shapes olfactory function. Scientific Reports, 8(1), 1296. https://doi.org/10.1038/s41598-018-19438-3

Koskinen, S., Kälviäinen, N., \& Tuorila, H. (2003). Flavor enhancement as a tool for increasing pleasantness and intake of a snack product among the elderly. Appetite, 41(1), 87-96. https://doi. org/10.1016/s0195-6663(03)00054-0

Koskinen, S., \& Tuorila, H. (2005). Performance on an odor detection and identification test as a predictor of ortho- and retronasal odor intensity ratings in the young and elderly. Food Quality and Preference, 16(5), 383-392. https://doi.org/10.1016/j.foodqual.2004.10.006

Kremer, S., Holthuysen, N., \& Boesveldt, S. (2014). The influence of olfactory impairment in vital, independently living older persons on their eating behaviour and food liking. Food Quality and Preference, 38, 30-39. https://doi.org/10.1016/j.foodqual.2014.05.012

Larsson, M., \& Bäckman L. (1993). Semantic activation and episodic odor recognition in young and older adults. Psychology and Aging, 8(4), 582-588. https://doi.org/10.1037//0882-7974.8.4.582. PMID: 8292286.

Larsson, M., \& Bäckman L. (1997) Age-related differences in episodic odour recognition: The role of access to specific odour names. Memory, 5(3), 361-378. https://doi.org/10.1080/741941391. PMID: 9231148.

Larsson, M., Farde, L., Hummel, T., Witt, M., Lindroth, N. E., \& Bäckman, L. (2009). Age-related loss of olfactory sensitivity: Association to dopamine transporter binding in putamen. Neuroscience, 161(2), 422-426. https://doi.org/10.1016/j.neuroscience.2009.03.074

Larsson, M., Finkel, D., \& Pedersen, N. L. (2000). Odor identification: Influences of age, gender, cognition, and personality. The Journals of Gerontology Series B: Psychological Sciences and Social Sciences, 55(5), 304-310. https://doi.org/10.1093/geronb/55.5.p304

Larsson, M., Hedner, M., \& Olofsson, J. (2009). Differential age and sex effects in semantic recognition of odors and words. Acta Psychologica Sinica, 41(11), 1049-1053. https://doi.org/10.3724/sp.j.1041. 2009.01049

Larsson, M., Hedner, M., Papenberg, G., Seubert, J., Bäckman, L., \& Laukka, E. J. (2016). Olfactory memory in the old and very old: Relations to episodic and semantic memory and APOE genotype. Neurobiology of Aging, 38, 118-126. https://doi.org/10.1016/j.neurobiolaging.2015.11.012

Larsson, M., Nilsson, L-G., Olofsson, J. K., \& Nordin, S. (2004). Demographic and cognitive predictors of cued odor identification: Evidence from a population-based study. Chemical Senses, 29(6), 547-554. https://doi.org/10.1093/chemse/bjh059

Larsson, M., Öberg, C., \& Bäckman L. (2005). Odor identification in old age: Demographic, sensory and cognitive correlates. Neuropsychology, Development, and Cognition. Section B, Aging, Neuropsychology and Cognition, 12(3), 231-244. https://doi.org/10.1080/138255890968385. PMID: 24428335.

Laws, S. M., Clarnette, R. M., Taddei, K., Martins, G., Paton, A., Almeida, O. P., Förstl, H., \& Martins, R. N. (2002). Association between the presenilin-1 mutation Glu318Gly and complaints of memory impairment. Neurobiology of Aging, 23(1), 55-58. https://doi.org/10.1016/s0197-4580(01) 00254-8

Lee, Y. H., Bak, Y., Park, C. H., Chung, S. J., Yoo, H. S., Baik, K., Jung, J. H., Sohn, Y. H., Shin, N. Y., \& Lee, P. H. (2020). Patterns of olfactory functional networks in Parkinson's disease dementia and Alzheimer's dementia. Neurobiology of Aging, 89, 63-70. https://doi.org/10.1016/j.neurobio laging.2019.12.021

Liu, B., Luo, Z., Pinto, J. M., Shiroma, E. J., Tranah, G. J., Wirdefeldt, K., Fang, F., Harris, T. B., \& Chen, H. (2019). Relationship between poor olfaction and mortality among communitydwelling older adults: A cohort study. Annals of Internal Medicine, 170(10), 673. https://doi.org/ 10.7326/m18-0775 
Lötsch, J., \& Hummel, T. (2006). The clinical significance of electrophysiological measures of olfactory function. Behavioural Brain Research, 170(1), 78-83. https://doi.org/10.1016/j.bbr.2006.02.013

Lucchini, R., Dorman, D., Elder, A., \& Veronesi, B. (2012). Neurological impacts from inhalation of pollutants and the nose-brain connection. NeuroToxicology, 33(4), 838-841. https://doi.org/10. $1016 /$ j.neuro.2011.12.001

MacIntosh, C., Morley, J. E., \& Chapman, I. M. (2000). The anorexia of aging. Nutrition, 16(10), 983-995. https://doi.org/10.1016/s0899-9007(00)00405-6

Mainland, J. D., Keller, A., Li, Y. R., Zhou, T., Trimmer, C., Snyder, L. L., Moberly, A. H., Adipietro, K. A., Liu, W. L. L., Zhuang, H., Zhan, S., Lee, S. S., Lin, A., \& Matsunami, H. (2014). The missense of smell: Functional variability in the human odorant receptor repertoire. Nature Neuroscience, 17(1), 114-120. https://doi.org/10.1038/nn.3598

Makowska, I., Kloszewska, I., Grabowska, A., Szatkowska, I., \& Rymarczyk, K. (2011). Olfactory deficits in normal aging and Alzheimer's disease in the polish elderly population. Archives of Clinical Neuropsychology, 26(3), 270-279. https://doi.org/10.1093/arclin/acr011

Mattes-Kulig, D. A., \& Henkin, R. I. (1985). Energy and nutrient consumption of patients with dysgeusia. Journal of the American Dietetic Association, 85(7), 822-826.

Mennella, J. A., \& Beauchamp, G. K. (1993). The effects of repeated exposure to garlic-flavored milk on the nursling's behavior. Pediatric Research, 34(6), 805-808. https://doi.org/10.1203/ 00006450-199312000-00022

Mennella, J. A., Johnson, A., \& Beauchamp, G. K. (1995). Garlic ingestion by pregnant women alters the odor of amniotic fluid. Chemical Senses, 20(2), 207-209. https://doi.org/10.1093/chemse/20.2. 207

Menon, C., Westervelt, H. J., Jahn, D. R., Dressel, J. A., \& O'Bryant, S. E. (2013). Normative performance on the brief smell identification test (BSIT) in a multi-ethnic bilingual cohort: A Project FRONTIER study. The Clinical Neuropsychologist, 27(6), 946-961. https://doi.org/10.1080/ 13854046.2013.796406

Morgan, C. D., \& Murphy, C. (2010). Differential effects of active attention and age on event-related potentials to visual and olfactory stimuli. International Journal of Psychophysiology, 78(2), 190-199. https://doi.org/10.1016/j.ijpsycho.2010.07.008

Murphy, C. (1985). Cognitive and chemosensory influences on age-related changes in the ability to identify blended foods. Journal of Gerontology, 40(1), 47-52. https://doi.org/10.1093/geronj/40.1.47

Murphy, C., Bacon, A. W., Bondi, M. W., \& Salmon, D. P. (1998). Apolipoprotein E status is associated with odor identification deficits in nondemented older persons. Annals of the New York Academy of Sciences, 855(1), 744-750. https://doi.org/10.1111/j.1749-6632.1998.tb10654.x

Murphy, C., Morgan, C. D., Geisler, M. W., Wetter, S., Covington, J. W., Madowitz, M. D., Nordin, S., \& Polich, J. M. (2000). Olfactory event-related potentials and aging: Normative data. International Journal of Psychophysiology, 36(2), 133-145. https://doi.org/10.1016/s0167-8760(99)00107-5

Murphy, C., Nordin, S., \& Acosta, L. (1997). Odor learning, recall, and recognition memory in young and elderly adults. Neuropsychology, 11(1), 126-137. https://doi.org/10.1037/0894-4105.11.1.126

Murphy, C., Schubert, C., Cruickshanks, K. J., Klein, B. E., Klein, R., \& Nondahl, D. M. (2002). Prevalence of olfactory impairment in older adults. The Journal of the American Medical Association, 288(18), 2307-2312. https://doi.org/10.1001/jama.288.18.2307

Nathan, B. P., Nannapaneni, S., Gairhe, S., Nwosu, I., \& Struble, R. G. (2007). The distribution of apolipoprotein E in mouse olfactory epithelium. Brain Research, 1137, 78-83. https://doi.org/10. 1016/j.brainres.2006.12.036

Niedenthal, S., Lundén, P., Ehrndal, M., \& Olofsson, J. K. (2019). A handheld olfactory display for smell-enabled VR games. 2019 IEEE international symposium on olfaction and electronic nose (ISOEN) (pp. 1-4). https://doi.org/10.1109/ISOEN.2019.8823162

Niedenthal, S., Nilsson, J., Larsson, M., \& Olofsson, J. (2021). A method for computerized olfactory assessment and training outside of laboratory or clinical settings. i-Perception, 12(3). https://doi.org/ $10.1177 / 20416695211023953$ 
Nordin, S., Almkvist, O., \& Berglund, B. (2012). Is loss in odor sensitivity inevitable to the aging individual? A study of "successfully aged" elderly. Chemosensory Perception, 5(2), 188-196. https:// doi.org/10.1007/s12078-011-9102-8

Nordin, S., Broman, D. A., Garvill, J., \& Nyroos, M. (2004). Gender differences in factors affecting rejection of food in healthy young Swedish adults. Appetite, 43(3), 295-301. https://doi.org/10.1016/ j.appet.2004.07.002

Nordin, S., Monsch, A. U., \& Murphy, C. (1995). Unawareness of smell loss in normal aging and Alzheimer's disease: Discrepancy between self-reported and diagnosed smell sensitivity. The Journals of Gerontology Series B: Psychological Sciences and Social Sciences, 50B(4), 187-192. https://doi.org/10.1093/geronb/50b.4.p187

Oberdörster, G., Sharp, Z., Atudorei, V., Elder, A., Gelein, R., Kreyling, W., \& Cox, C. (2004). Translocation of Inhaled Ultrafine Particles to the Brain. Inhalation Toxicology, 16(6-7), 437-445. https://doi.org/10.1080/08958370490439597

Oleszkiewicz, A., Schriever, V. A., Croy, I., Hähner, A., \& Hummel, T. (2019). Updated Sniffin' sticks normative data based on an extended sample of 9139 subjects. European Archives of Oto-RhinoLaryngology, 276(3), 719-728. https://doi.org/10.1007/s00405-018-5248-1

Olofsson, J. K., Rogalski, E., Harrison, T., Mesulam, M. M., \& Gottfried, J. A. (2013). A cortical pathway to olfactory naming: evidence from primary progressive aphasia. Brain: a journal of neurology, 136(Pt 4), 1245-1259. https://doi.org/10.1093/brain/awt019

Olofsson, J. K., Ekström, I., Lindström, J., Syrjänen, E., Stigsdotter-Neely, A., Nyberg, L., Jonsson, S., \& Larsson, M. (2020). Smell-based memory training: Evidence of olfactory learning and transfer to the visual domain. Chemical Senses, 45(7), 593-600. https://doi.org/10.1093/chemse/bjaa049

Olofsson, J. K., \& Gottfried, J. A. (2015). The muted sense: Neurocognitive limitations of olfactory language. Trends in Cognitive Sciences, 19(6), 314-321. https://doi.org/10.1016/j.tics.2015.04.007

Olofsson, J. K., Hurley, R. S., Bowman, N. E., Bao, X., Mesulam, M. M., \& Gottfried, J. A. (2014). A designated odor-language integration system in the human brain. The Journal of Neuroscience, 34(45), 14864-14873. https://doi.org/10.1523/JNEUROSCI.2247-14.2014

Olofsson, J. K., Josefsson, M., Ekström, I., Wilson, D., Nyberg, L., Nordin, S., Nordin Adolfsson, A., Adolfsson, R., Nilsson, L.-G., \& Larsson, M. (2016). Long-term episodic memory decline is associated with olfactory deficits only in carriers of ApoE-e4. Neuropsychologia, 85, 1-9. https://doi.org/ 10.1016/j.neuropsychologia.2016.03.004

Olofsson, J. K., Larsson, M., Roa, C., Wilson, D. A., \& Jonsson Laukka, E. (2020). Interaction between odor identification deficit and APOE4 predicts 6-year cognitive decline in elderly individuals. Behavior Genetics, 50(1), 3-13. https://doi.org/10.1007/s10519-019-09980-9

Olofsson, J. K., Nordin, S., Wiens, S., Hedner, M., Nilsson, L.-G., \& Larsson, M. (2010). Odor identification impairment in carriers of ApoE- $\varepsilon 4$ is independent of clinical dementia. Neurobiology of Aging, 31(4), 567-577. https://doi.org/10.1016/j.neurobiolaging.2008.05.019

Olofsson, J. K., Rönnlund, M., Nordin, S., Nyberg, L., Nilsson, L.-G., \& Larsson, M. (2009). Odor identification deficit as a predictor of five-year global cognitive change: Interactive effects with age and ApoE-84. Behavior Genetics, 39(5), 496-503. https://doi.org/10.1007/s10519009-9289-5

Pagano, S. F., Impagnatiello, F., Girelli, M., Cova, L., Grioni, E., Onofri, M., Cavallaro, M., Etteri, S., Vitello, F., Giombini, S., Solero, C. L., \& Parati, E. A. (2000). Isolation and Characterization of Neural Stem Cells from the Adult Human Olfactory Bulb. Stem Cells, 18(4), 295-300. https://doi. org/10.1634/stemcells.18-4-295

Palta, P., Chen, H., Deal, J. A., Sharrett, A. R., Gross, A., Knopman, D., Griswold, M., Heiss, G., \& Mosley, T. H. (2018). Olfactory function and neurocognitive outcomes in old age: The Atherosclerosis Risk in Communities Neurocognitive Study. Alzheimer's \& Dementia, 14(8), 1015-1021. https://doi.org/10.1016/j.jalz.2018.02.019

Pekala, K., Chandra, R. K., \& Turner, J. H. (2016). Efficacy of olfactory training in patients with olfactory loss: A systematic review and meta-analysis. International Forum of Allergy \& Rhinology, 6(3), 299-307. https://doi.org/10.1002/alr.21669 
Pelchat, M. L. (2000). You can teach an old dog new tricks: Olfaction and responses to novel foods by the elderly. Appetite, 35(2), 153-160. https://doi.org/10.1006/appe.2000.0348

Pinto, J. M., Schumm, L. P., Wroblewski, K. E., Kern, D. W., \& McClintock, M. K. (2014). Racial disparities in olfactory loss among older adults in the United States. The Journals of Gerontology: Series A, 69A(3), 323-329. https://doi.org/10.1093/gerona/glt063

Rahayel, S., Frasnelli, J., \& Joubert, S. (2012). The effect of Alzheimer's disease and Parkinson's disease on olfaction: A meta-analysis. Behavioural Brain Research, 231(1), 60-74. https://doi.org/ 10.1016/j.bbr.2012.02.047

Ranft, U., Schikowski, T., Sugiri, D., Krutmann, J., \& Krämer, U. (2009). Long-term exposure to traffic-related particulate matter impairs cognitive function in the elderly. Environmental Research, 109(8), 1004-1011. https://doi.org/10.1016/j.envres.2009.08.003

Rawal, S., Hoffman, H. J., Chapo, A. K., \& Duffy, V. B. (2014). Sensitivity and specificity of selfreported olfactory function in a home-based study of independent-living, healthy older women. Chemosensory Perception, 7(3-4), 108-116. https://doi.org/10.1007/s12078-014-9170-7

Rawson, N. E. (2006). Olfactory loss in aging. Science of Aging Knowledge Environment, 2006(5), pe6. https://doi.org/10.1126/sageke.2006.5.pe6

Rawson, N. E., Gomez, G., Cowart, B., \& Restrepo, D. (1998). The use of olfactory receptor neurons (ORNs) from biopsies to study changes in aging and neurodegenerative diseases. Annals of the New York Academy of Sciences, 855(1), 701-707. https://doi.org/10.1111/j.1749-6632.1998.tb10648.x

Reichert, J. L., \& Schöpf, V. (2018). Olfactory loss and regain: Lessons for neuroplasticity. The Neuroscientist, 24(1), 22-35. https://doi.org/10.1177/1073858417703910

Reijs, B. L. R., Ramakers, I. H. G. B., Elias-Sonnenschein, L., Teunissen, C. E., Koel-Simmelink, M., Tsolaki, M., Wahlund, L.-O., Waldemar, G., Hausner, L., Johannsen, P., Vanderstichele, H., Verhey, F., Devanand, D. P., \& Visser, P. J. (2017). Relation of Odor Identification with Alzheimer's Disease Markers in Cerebrospinal Fluid and Cognition. Journal of Alzheimer's Disease, 60(3), 1025-1034. https://doi-org.ezp.sub.su.se/10.3233/JAD-170564

Richardson, C. T., Walsh, J. H., Cooper, K. A., Feldman, M., \& Fordtran, J. S. (1977). Studies on the role of cephalic-vagal stimulation in the acid secretory response to eating in normal human subjects. The Journal of Clinical Investigation, 60(2), 435-441. https://doi.org/10.1172/JCI108793

Roberts, R. O., Christianson, T. J., Kremers, W. K., Mielke, M. M., Machulda, M. M., Vassilaki, M., Alhurani, R. E., Geda, Y. E., Knopman, D. S., \& Petersen, R. C. (2016). Association Between Olfactory Dysfunction and Amnestic Mild Cognitive Impairment and Alzheimer Disease Dementia. JAMA neurology, 73(1), 93-101. https://doi.org/10.1001/jamaneurol.2015.2952

Rolls, B. J., \& McDermott, T. M. (1991). Effects of age on sensory-specific satiety. The American Journal of Clinical Nutrition, 54(6), 988-996. https://doi.org/10.1093/ajen/54.6.988

Rolls, E. T. (2015). Taste, olfactory, and food reward value processing in the brain. Progress in Neurobiology, 127-128, 64-90. https://doi.org/10.1016/j.pneurobio.2015.03.002

Saletti, A., Lindgren, E. Y., Johansson, L., \& Cederholm, T. (2000). Nutritional status according to Mini Nutritional Assessment in an institutionalized elderly population in Sweden. Gerontology, 46(3), 139-145. https://doi.org/10.1159/000022149

Santos, D. V., Reiter, E. R., DiNardo, L. J., \& Costanzo, R. M. (2004). Hazardous events associated with impaired olfactory function. Archives of otolaryngology-head \& neck surgery, 130(3), 317-319. https://doi.org/10.1001/archotol.130.3.317

Savic, I., Gulyas, B., Larsson, M., \& Roland, P. (2000). Olfactory functions are mediated by parallel and hierarchical processing. Neuron, 26(3), 735-745. https://doi.org/10.1016/s0896-6273(00)81209-x

Schaal, B., Marlier, L., \& Soussignan, R. (1998). Olfactory function in the human fetus: Evidence from selective neonatal responsiveness to the odor of amniotic fluid. Behav Neurosci, 112(6), 1438-1449. https://doi.org/10.1037//0735-7044.112.6.1438 PMID: 9926826.

Schiffman, S. S. (1991). Drugs influencing taste and smell perception. In T. V. Getchell, L. M. Bartoshuk, R. L. Doty, \& J. B. Snow (Eds.), Smell and taste in health and disease (1st ed., pp. 845-850). Raven Press.

Schiffman, S. S. (1997). Taste and smell losses in normal aging and disease. The Journal of the American Medical Association, 278(16), 1357. https://doi.org/10.1001/jama.1997.03550160077042 
Schiffman, S. S. (1998). Sensory enhancement of foods for the elderly with monosodium glutamate and flavors. Food Reviews International, 14(2-3), 321-333. https://doi.org/10.1080/87559129809541164

Schiffman, S. S., \& Miletic, I. D. (1999). Effect of taste and smell on secretion rate of salivary IgA in elderly and young persons. The Journal of Nutrition, Health \& Aging, 3(3), 158-164.

Schiffman, S. S., \& Warwick, Z. S. (1988). Flavor enhancement of foods for the elderly can reverse anorexia. Neurobiology of Aging, 9, 24-26. https://doi.org/10.1016/s0197-4580(88)80009-5

Schiffman, S. S., \& Warwick, Z. S. (1993). Effect of flavor enhancement of foods for the elderly on nutritional status: Food intake, biochemical indices, and anthropometric measures. Physiology \& Behavior, 53(2), 395-402. https://doi.org/10.1016/0031-9384(93)90224-4

Schiffman, S. S., \& Zervakis, J. (2002). Taste and smell perception in the elderly: Effect of medications and disease. Advances in Food and Nutrition Research, 44, 247-346. https://doi.org/10.1016/s10434526(02)44006-5

Schubert, C. R., Cruickshanks, K. J., Fischer, M. E., Huang, G.-H., Klein, R., Pankratz, N., Zhong, W., \& Nondahl, D. M. (2013). Odor identification and cognitive function in the Beaver Dam Offspring Study. Journal of Clinical and Experimental Neuropsychology, 35(7), 669-676. https:// doi.org/10.1080/13803395.2013.809701

Schubert, C. R., Cruickshanks, K. J., Klein, B. E. K., Klein, R., \& Nondahl, D. M. (2011). Olfactory impairment in older adults: Five-year incidence and risk factors. The Laryngoscope, 121(4), 873-878. https://doi.org/10.1002/lary.21416

Schubert, C. R., Fischer, M. E., Pinto, A. A., Klein, B. E. K., Klein, R., \& Cruickshanks, K. J. (2017). Odor detection thresholds in a population of older adults. The Laryngoscope, 127(6), 1257-1262. https://doi.org/10.1002/lary.26457

Seiberling, K. A., \& Conley, D. B. (2004). Aging and olfactory and taste function. Otolaryngologic clinics of North America, 37(6), 1209-vii. https://doi.org/10.1016/j.otc.2004.06.006

Seubert, J., Laukka, E. J., Rizzuto, D., Hummel, T., Fratiglioni, L., Bäckman, L., \& Larsson, M. (2017). Prevalence and correlates of olfactory dysfunction in old age: A population-based study. The Journals of Gerontology: Series A, 72(8), 1072-1079. https://doi.org/10.1093/gerona/glx054

Ship, J. A. (1999). The Influence of Aging on Oral Health and Consequences for Taste and Smell. Physiology \& Behavior, 66(2), 209-215. https://doi.org/10.1016/s0031-9384(98)00267-4

Silva, M., Viveiros, C. P., Kotsifas, N., Duarte, A., Dib, E., Mercer, P., Pessoa, R. R., \& Witt, M. (2019). Olfactory impairment in frontotemporal dementia: A systematic review and meta-analysis. Dementia \& neuropsychologia, 13(2), 154-161. https://doi.org/10.1590/1980-57642018dn13-020003

Solemdal, K., Sandvik, L., Willumsen, T., Mowe, M., \& Hummel, T. (2012). The impact of oral health on taste ability in acutely hospitalized elderly. PLoS One, 7(5), e36557. https://doi.org/10.1371/ journal.pone. 0036557

Stanciu, I., Larsson, M., Nordin, S., Adolfsson, R., Nilsson, L. G., \& Olofsson, J. K. (2014). Olfactory Impairment and Subjective Olfactory Complaints Independently Predict Conversion to Dementia: A Longitudinal, Population-Based Study. Journal of the International Neuropsychological Society, 20(2), 209-217. https://doi.org/10.1017/s1355617713001409

Stevens, D. A., \& Lawless, H. T. (1981). Age-related changes in flavor perception. Appetite, 2(2), 127-136. https://doi.org/10.1016/s0195-6663(81)80006-2

Stevens, J. C., \& Cain, W. S. (1985). Age-related deficiency in the perceived strength of six odorants. Chemical Senses, 10(4), 517-529. https://doi.org/10.1093/chemse/10.4.517

Stevens, J. C., \& Cain, W. S. (1986). Smelling via the mouth: Effect of aging. Perception \& Psychophysics, 40(3), 142-146. https://doi.org/10.3758/bf03203009

Stevens, J. C., \& Cain, W. S. (1987). Old-age deficits in the sense of smell as gauged by thresholds, magnitude matching, and odor identification. Psychology and Aging, 2(1), 36-42. https://doi.org/10. 1037/0882-7974.2.1.36

Stevens, J. C., \& Cain, W. S. (1993). Changes in taste and flavor in aging. Critical Reviews in Food Science and Nutrition, 33(1), 27-37. https://doi.org/10.1080/10408399309527609

Stevens, J. C., Cain, W. S., Schiet, F. T., \& Oatley, M. W. (1989). Olfactory adaptation and recovery in old age. Perception, 18(2), 265-276. https://doi.org/10.1068/p180265 
Stevens, J. C., Plantinga, A., \& Cain, W. S. (1982). Reduction of odor and nasal pungency associated with aging. Neurobiology of Aging, 3(2), 125-132. https://doi.org/10.1016/0197-4580(82)90008-2

Striepens, N., Scheef, L., Wind, A., Meiberth, D., Popp, J., Spottke, A., Kölsch, H., Wagner, M., \& Jessen, F. (2011). Interaction effects of subjective memory impairment and ApoE4 genotype on episodic memory and hippocampal volume. Psychological Medicine, 41(9), 1997-2006. https://doiorg.ezp.sub.su.se/10.1017/S0033291711000067

Struble, R. G., Short, J., Ghobrial, M., \& Nathan, B. P. (1999). Apolipoprotein E immunoreactivity in human and mouse olfactory bulb. Neuroscience Letters, 267(2), 137-140. https://doi.org/10.1016/ s0304-3940(99)00352-3

Stuck, B. A., Frey, S., Freiburg, C., Hörmann, K., Zahnert, T., \& Hummel, T. (2006). Chemosensory event-related potentials in relation to side of stimulation, age, sex, and stimulus concentration. Clinical Neurophysiology, 117(6), 1367-1375. https://doi.org/10.1016/j.clinph.2006.03.004

Sulmont-Rosse, C., Maitre, I., Amand, M., Symoneaux, R., Van Wymelbeke, V., Caumon, E., Tavares, J., \& Issanchou, S. (2015). Evidence for different patterns of chemosensory alterations in the elderly population: Impact of age versus dependency. Chemical Senses, 40(3), 153-164. https://doi.org/10.1093/chemse/bju112

Sun, G. H., Raji, C. A., Maceachern, M. P., \& Burke, J. F. (2012). Olfactory identification testing as a predictor of the development of Alzheimer's dementia: a systematic review. The Laryngoscope, 122(7), 1455-1462. https://doi-org.ezp.sub.su.se/10.1002/lary.23365

Suzuki, Y., Critchley, H. D., Suckling, J., Fukuda, R., Williams, S. C. R., Andrew, C., Howard, R., Ouldred, E., Bryant, C., Swift, C. G., \& Jackson, S. H. D. (2001). Functional magnetic resonance imaging of odor identification: The effect of aging. The Journals of Gerontology Series A: Biological Sciences and Medical Sciences, 56(12), M756-M760. https://doi.org/10.1093/gerona/56.12.m756

Swan, G. E., \& Carmelli, D. (2002). Impaired olfaction predicts cognitive decline in nondemented older adults. Neuroepidemiology, 21(2), 58-67. https://doi.org/10.1159/000048618

Swedish National Food Administration. (1998), Mat och kostbehandling för äldre: Problem och möjligheter [Food and diet treatment for the elderly: Problems and opportunities]. Livsmedelsverket.

Tebrügge, S., Winkler, A., Gerards, D., Weimar, C., Moebus, S., Jöckel, K.-H., Erbel, R., \& Jokisch, M. (2018). Olfactory function is associated with cognitive performance: Results of the Heinz Nixdorf recall study. Journal of Alzheimer's Disease, 63(1), 319-329. https://doi.org/10.3233/jad170863

Temmel, A. F. P., Quint, C., Schickinger-Fischer, B., Klimek, L., Stoller, E., \& Hummel, T. (2002). Characteristics of olfactory disorders in relation to major causes of olfactory loss. Archives of Otolaryngology-Head \& Neck Surgery, 128(6), 635. https://doi.org/10.1001/archotol.128.6.635

Toussaint, N., de Roon, M., van Campen, J. P. C. M., Kremer, S., \& Boesveldt, S. (2015). Loss of olfactory function and nutritional status in vital older adults and geriatric patients. Chemical Senses, 40(3), 197-203. https://doi.org/10.1093/chemse/bju113

Van Regemorter, V., Hummel, T., Rosenzweig, F., Mouraux, A., Rombaux, P., \& Huart, C. (2020). Mechanisms linking olfactory impairment and risk of mortality. Frontiers in Neuroscience, 14, 140. https://doi.org/10.3389/fnins.2020.00140

Vellas, B., Lauque, S., Andrieu, S., Nourhashemi, F., Rolland, Y., Baumgartner, R., \& Garry, P. (2001). Nutrition assessment in the elderly. Current Opinion in Clinical Nutrition and Metabolic Care, 4(1), 5-8. https://doi.org/10.1097/00075197-200101000-00002

Wang, J., Eslinger, P. J., Smith, M. B., \& Yang, Q. X. (2005). Functional magnetic resonance imaging study of human olfaction and normal aging. The Journals of Gerontology Series A: Biological Sciences and Medical Sciences, 60(4), 510-514. https://doi.org/10.1093/gerona/60.4.510

Wang, J., Sun, X., \& Yang, Q. X. (2017). Early aging effect on the function of the human central olfactory system. The Journals of Gerontology Series A: Biological Sciences and Medical Sciences, 72(8), 1007-1014. https://doi.org/10.1093/gerona/glw104

Watabe-Rudolph, M., Begus-Nahrmann, Y., Lechel, A., Rolyan, H., Scheithauer, M., Rettinger, G., Rudolf Thal, D., \& Lenhard Rudolph, K. (2011). Telomere shortening impairs regeneration of the olfactory epithelium in response to injury but not under homeostatic conditions. PLoS One, 6(11), e27801. https://doi-org.ezp.sub.su.se/10.1371/jour nal.pone.0027801 
Wegener, B.-A., Croy, I., Hähner, A., \& Hummel, T. (2017). Olfactory training with older people. International Journal of Geriatric Psychiatry, 33(1), 212-220. https://doi.org/10.1002/gps.4725

Wehling, E. I., Lundervold, A. J., Espeset, T., Reinvang, I., Bramerson, A., \& Nordin, S. (2015). Even cognitively well-functioning adults are unaware of their olfactory dysfunction: Implications for ENT clinicians and researchers. Rhinology Journal, 53(1), 89-94. https://doi.org/ $10.4193 /$ rhin 14.081

Wehling, E. I., Lundervold, A. J., Nordin, S., \& Wollschlaeger, D. (2016). Longitudinal changes in familiarity, free and cued odor identification, and edibility judgments for odors in aging individuals. Chemical Senses, 41(22), 155-161. https://doi.org/10.1093/chemse/bjv066

Wehling, E. I., Nordin, S., Espeseth, T., Reinvang, I., \& Lundervold, A. J. (2011). Unawareness of olfactory dysfunction and its association with cognitive functioning in middle aged and old adults. Archives of Clinical Neuropsychology, 26(3), 260-269. https://doi.org/10.1093/arclin/acr019

Wehling, E. I., Wollschlaeger, D., Nordin, S., \& Lundervold, A. J. (2016). Longitudinal changes in odor identification performance and neuropsychological measures in aging individuals. Neuropsychology, 30(1), 87-97. https://doi.org/10.1037/neu0000212

White, T. L., \& Kurtz, D. B. (2003). The relationship between metacognitive awareness of olfactory ability and age in people rReporting chemosensory disturbances. The American Journal of Psychology, 116(1), 99. https://doi.org/10.2307/1423337

Wilson, R. S., Arnold, S. E., Tang, Y., \& Bennett, D. A. (2006). Odor identification and decline in different cognitive domains in old age. Neuroepidemiology, 26(2), 61-67. https://doi.org/10.1159/ 000090250

Wilson, R. S., Yu, L., \& Bennett, D. A. (2011). Odor identification and mortality in old age. Chemical Senses, 36(1), 63-67. https://doi.org/10.1093/chemse/bjq098

Wong, K. K., Muller, M. L. T. M., Kuwabara, H., Studenski, S. A., \& Bohnen, N. I. (2010). Olfactory loss and nigrostriatal dopaminergic denervation in the elderly. Neuroscience Letters, 484(3), 163-167. https://doi.org/10.1016/j.neulet.2010.08.037

Wysocki, C. J., \& Gilbert, A. N. (1989). National geographic smell survey. Effects of age are heterogenous. Annals of the New York Academy of Sciences, 561, 12-28. https://doi.org/10.1111/j.17496632.1989.tb20966.x

Wysocki, C. J., \& Pelchat, M. L. (1993). The effects of aging on the human sense of smell and its relationship to food choice. Critical Reviews in Food Science and Nutrition, 33(1), 63-82. https://doi. org/10.1080/10408399309527613

Yaffe, K., Freimer, D., Chen, H., Asao, K., Rosso, A., Rubin, S., Tranah, G., Cummings, S., \& Simonsick, E. (2017). Olfaction and risk of dementia in a biracial cohort of older adults. Neurology, 88(5), 456-462. https://doi.org/10.1212/wnl.0000000000003558

Yousem, D. M., Geckle, R. J., Bilker, W. B., \& Doty, R. L. (1998). Olfactory bulb and tract and temporal lobe volumes: Normative data across decades. Annals of the New York Academy of Sciences, 855(1), 546-555. https://doi.org/10.1111/j.1749-6632.1998.tb10624.x

\section{How to cite this article}

Olofsson, J. K., Ekström, I., Larsson, M., \& Nordin, S. (2021). Olfaction and aging: A review of the current state of research and future directions. i-Perception, 12(3), 1-24. https://doi.org/10.1177/ 20416695211020331 